\title{
DEEP PENETRATION FLUORIDATION
}

Humanchemie is famous for caries prophylaxis and endodontic treatment but also for cavity and stump prevention.

The family-owned company's latest innovations are Tiefenfluorid (deeppenetration fluoridation) junior and the Depotphorese apparatus MAGIS. Tiefenfluorid junior offers a longer lasting and stronger remineralisation compared to

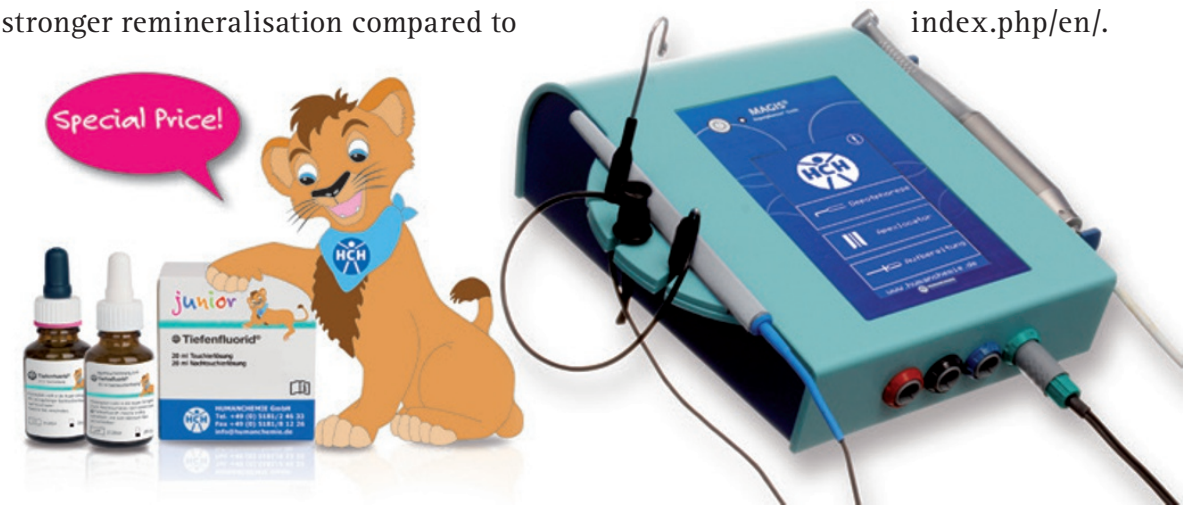

\section{PICK UP A FREE SAMPLE OF A TOP PRODUCT}

Visit the team from GSK Consumer Healthcare on stand P06 to find out about Sensodyne and Corsodyl products and to receive samples.

Sensodyne Repair \& Protect toothpaste contains NovaMin, an innovative desensitising agent which builds a robust, reparative layer over and within dentine tubules to provide clinically normal fluoridations - even in hard to reach areas - combined with a fruitysweet flavour. The MAGIS combines Depotphorese - a special root treatment even for elsewhere non-treatable teeth - and apex location in one apparatus. Equipment for conventional endodontic treatment is also available. For more information visit: www humanchemie de/ information visit: www.humanchemie.de/ 